\title{
Some aspects of man-made contamination on ULF measurements
}

\author{
U. Villante ${ }^{1,2}$, M. Vellante ${ }^{1,2}$, A. Piancatelli ${ }^{1,2}$, A. Di Cienzo ${ }^{2}$, T. L. Zhang $^{3}$, W. Magnes $^{3}$, V. Wesztergom ${ }^{4}$, and \\ A. Meloni ${ }^{5,2}$ \\ ${ }^{1}$ Dipartimento di Fisica, Università, L'Aquila, Italy \\ ${ }^{2}$ Consorzio Area di Ricerca in Astrogeofisica, L'Aquila, Italy \\ ${ }^{3}$ Institut für Weltraumforschung, Graz, Austria \\ ${ }^{4}$ Geodetic and Geophysical Research Institute of the Hungarian Academy of Science, Sopron, Hungary \\ ${ }^{5}$ Istituto Nazionale di Geofisica e Vulcanologia, Roma, Italy
}

Received: 30 April 2003 - Revised: 02 November 2003 - Accepted: 05 November 2003 - Published: 2 April 2004

\begin{abstract}
An analysis of the man made contamination on ULF measurements in highly populated areas has been conducted at several suitably chosen sites in Western Europe. The experimental results show common characteristics at different stations with clear evidence for an additional working day contamination with respect to weekends. These effects more clearly emerge in the vertical component that is less influenced by natural signals. A similar analysis conducted at Terra Nova Bay does not reveal any clear evidence for man made disturbances on Antarctic measurements.
\end{abstract}

Key words. (Magnetospheric physics, instruments and techniques; Solar wind-magnetosphere interaction) (Geomagnetism and paleomagnetism time variations, diurnal to secular)

\section{Introduction}

As it is well known, micropulsation measurements in the ULF frequency range $(0.001-10 \mathrm{~Hz})$ allow for interesting investigations of important aspects of the interaction between the solar wind and the Earth's magnetosphere and also provide useful information on the physical characteristics of the magnetospheric and ionospheric plasma populations (Lanzerotti et al., 1979, Webb et al., 1977, Vellante et al., 2002). These measurements, however, may be interesting also for other aspects of geophysical sciences: for example, geomagnetic field variations in the frequency range of micropulsations provide useful information on the structure of the Earth's crust (Meloni et al., 1985; Pilipenko and Fedorov, 1993; Vellante, 1997; Villante et al., 1998). In addition, local ULF emissions are considered a promising candidate for short-term earthquake predictions (Fraser-Smith et al., 1990, 1994; Molchanov et al., 1992; Hayakawa et al., 1996; Nagao et al., 2002; Gotoh et al., 2002). Lastly, special care has been dedicated to the possible influence of natural and artificial

Correspondence to: U. Villante

(umberto.villante@aquila.infn.it)
ULF electromagnetic fields on biological systems and human health (Villoresi et al., 1994; Breus et al., 1995; Ptitsyna et al., 1996). According to previous arguments, for several applications it might be useful to conduct ULF measurements not far from densely populated areas. On the other hand, some aspects of magnetospheric dynamics (wave propagation, resonance phenomena, global oscillation modes, etc.) request simultaneous measurements from large magnetometer networks that, in several cases, have been installed in highly populated regions. As a consequence, a careful evaluation of the possible contamination of man-made disturbances on ULF measurements (which, in general, mostly come from electric railways, power lines, electromechanical devices, car traffic) represents an important topic in a wide scientific context.

A previous analysis at a single site in Italy (Villante and Vellante, 1998) revealed an increased level of power (mostly between $45-500 \mathrm{mHz}$ ) during working days. In that case, however, some significant differences between components were imputed to the measuring system itself. Therefore, we found it interesting to conduct a similar analysis on data sets obtained at several low-latitude sites in Western Europe. Obviously, the relative importance of different noise sources may be not the same at different stations. Nevertheless, we found common characteristics of the experimental results at different sites; it makes us sure that our basic conclusions are not related with the registration site. The same analysis also was conducted on ULF measurements conducted at Terra Nova Bay (Antarctica).

At low latitudes, geomagnetic field fluctuations in the ULF band are mostly a Pc3 $(20-100 \mathrm{mHz})$ daytime phenomenon, characterized by two dominant oscillation modes: external waves (Pc3a) penetrating deep into the magnetosphere, and resonant oscillations (Pc3b) of local field lines at the fundamental eigenfrequency, decreasing with latitude (Villante and Vellante, 1997). Through the solar cycle, due to the variable interplanetary and magnetospheric conditions, the two modes become often intermingled: in general, however, Pc3a events have latitude independent frequency $(\sim 30-50 \mathrm{mHz})$ 
$\mathrm{H}$
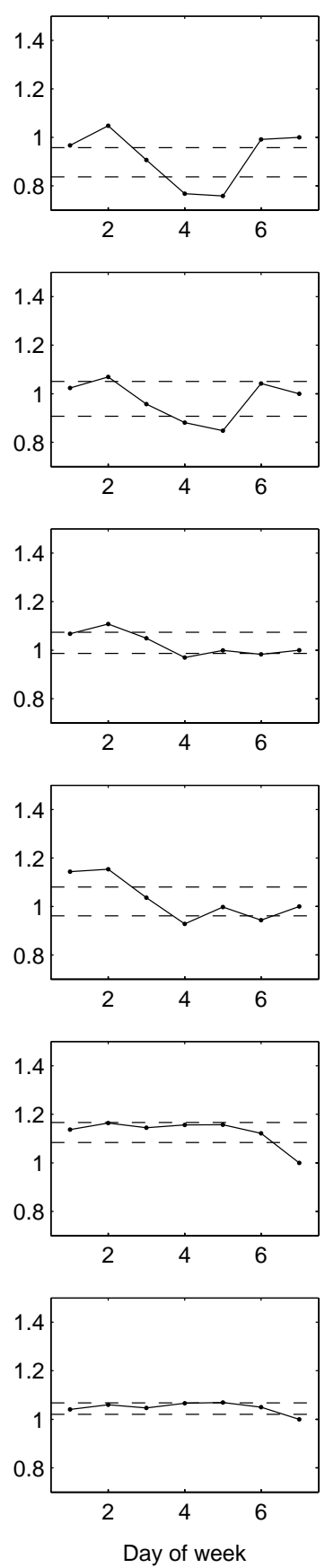

D
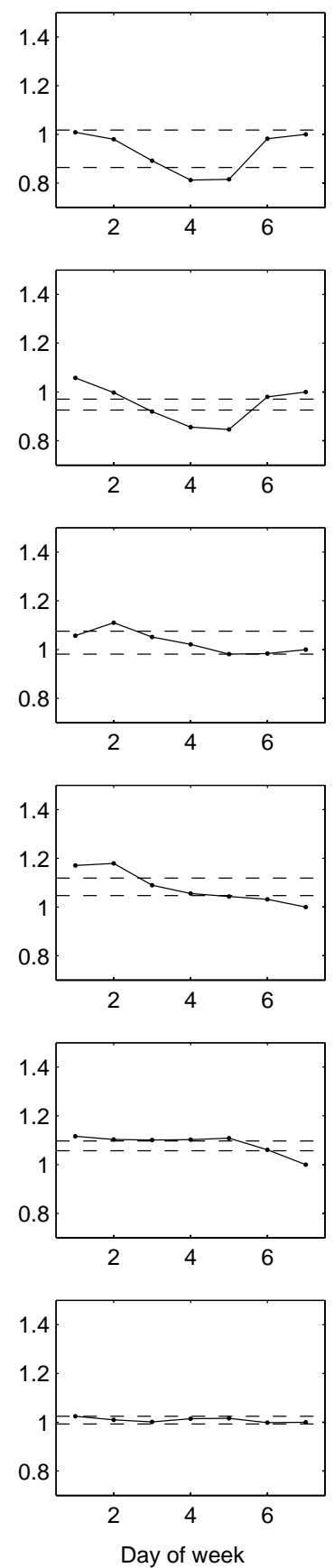

Station A (90\%) 6-18 LT
Z
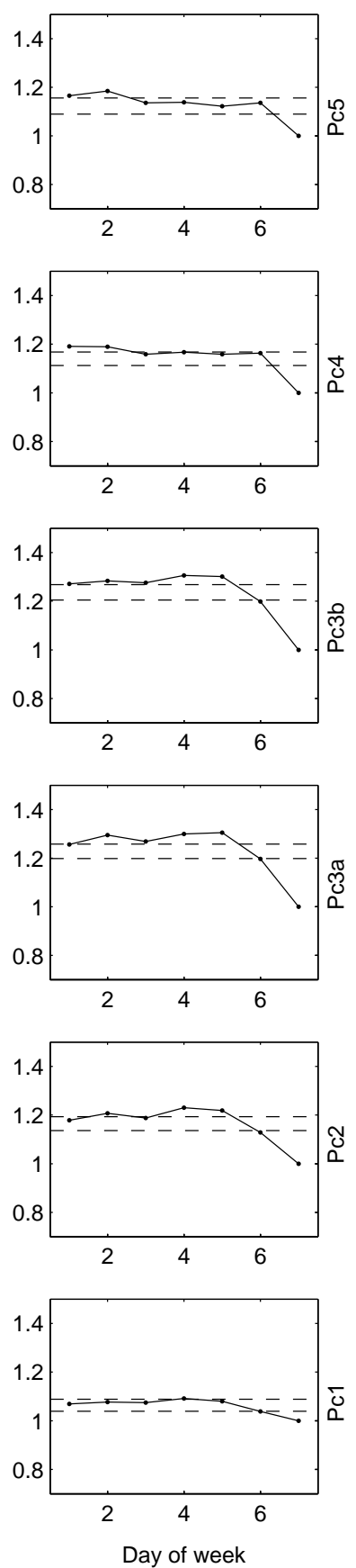

Day of week

Fig. 1. Weekly variation of the average daytime power of magnetic field components in different frequency bands at Station A (90\% of original spectra). Dashed lines identify the $99 \%$ confidence interval. 
(a)
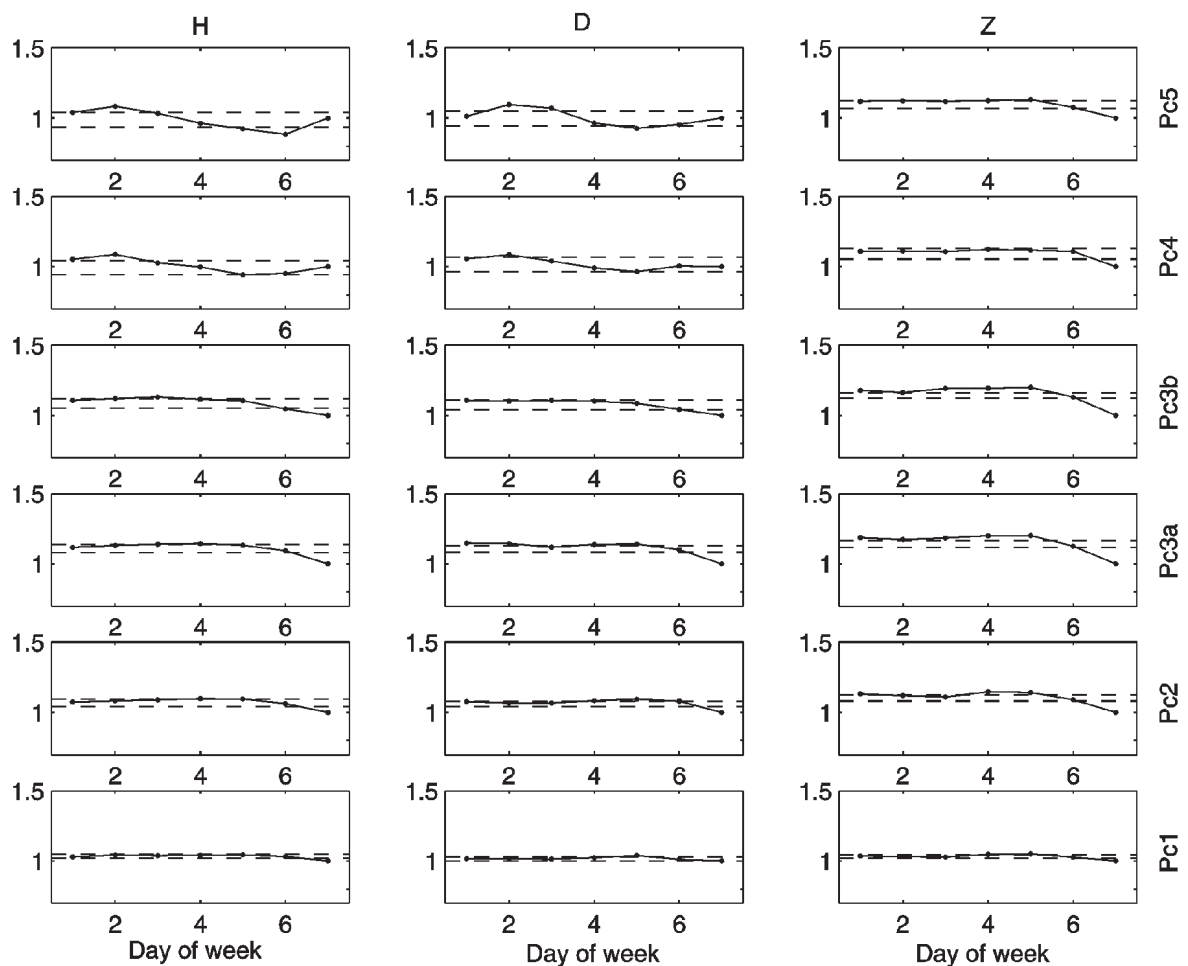

Station A (50\%) 6-18 LT

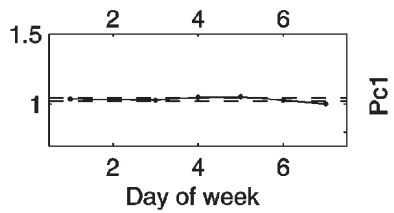

(b)
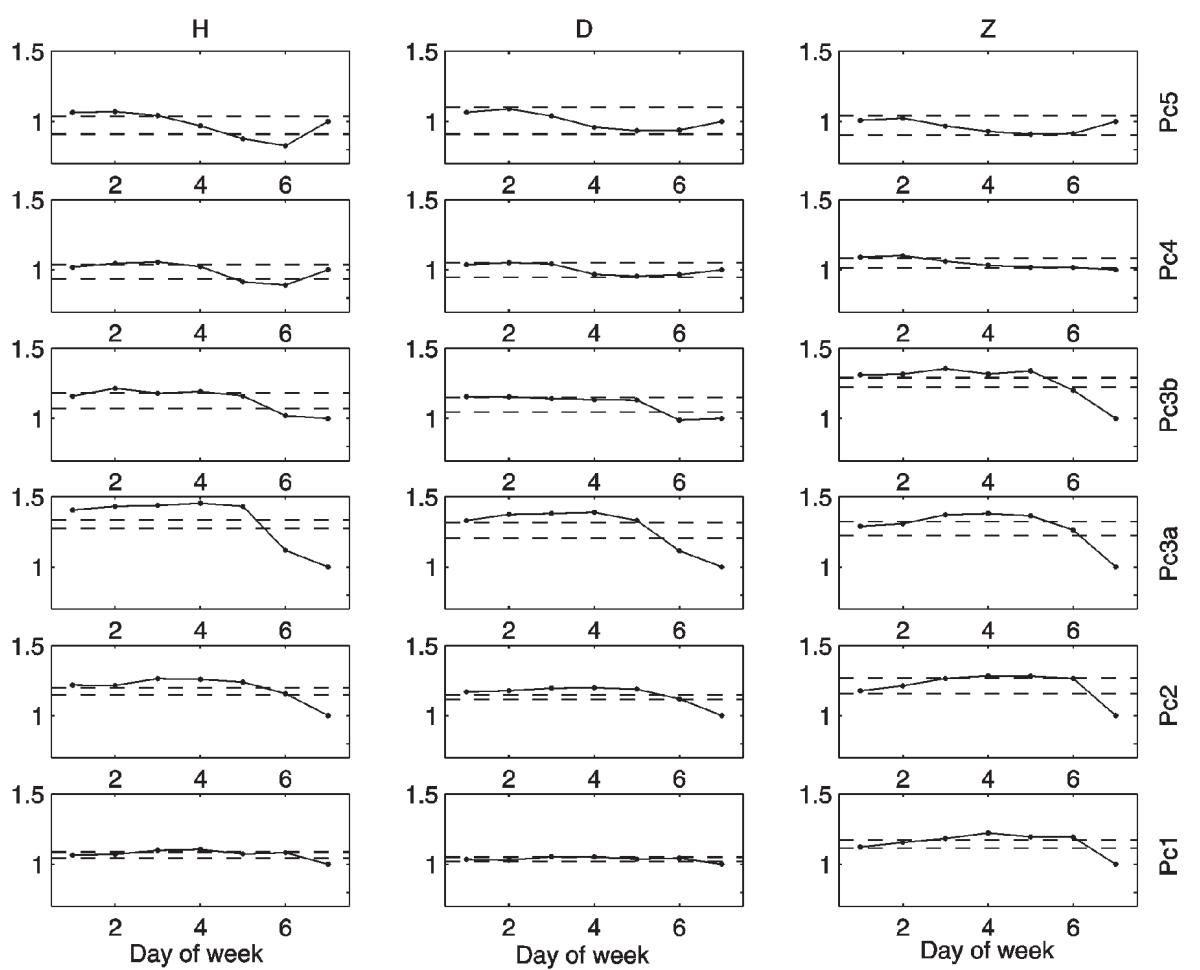

Station B (50\%) 6-18 LT

Fig. 2. Weekly variation of the daytime average power of magnetic field components in different frequency bands (50\% of original spectra). Dashed lines identify the $99 \%$ confidence interval. (a) Station A. (b) Station B. 
$\mathrm{H}$
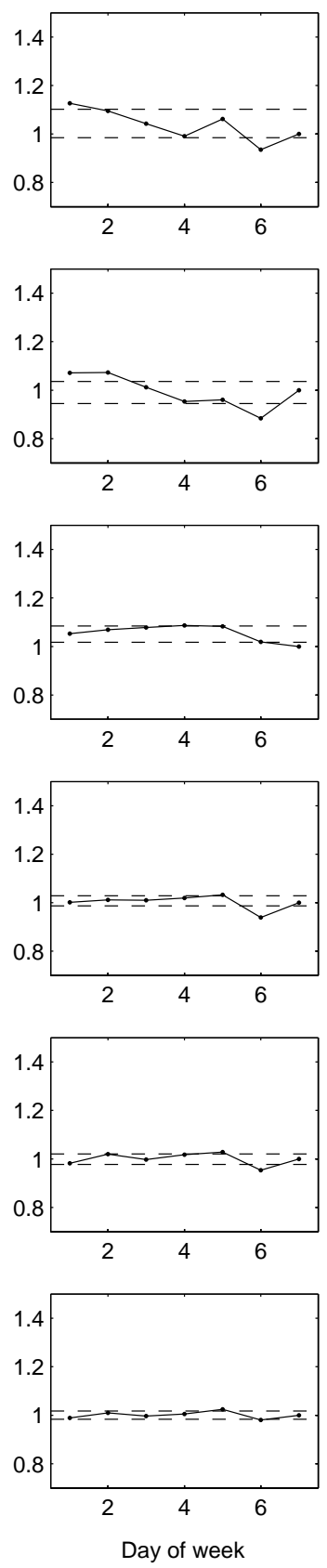

D
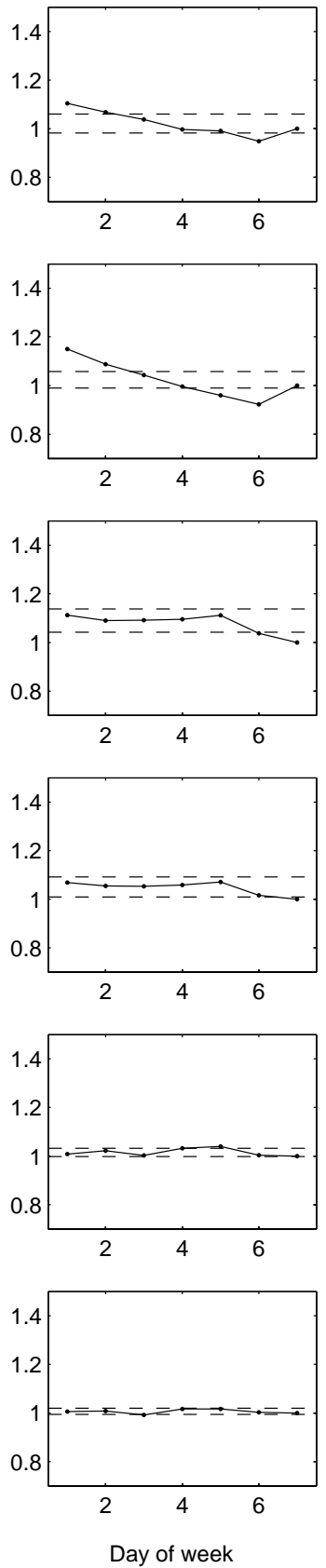

Station A (50\%) 18-6 LT
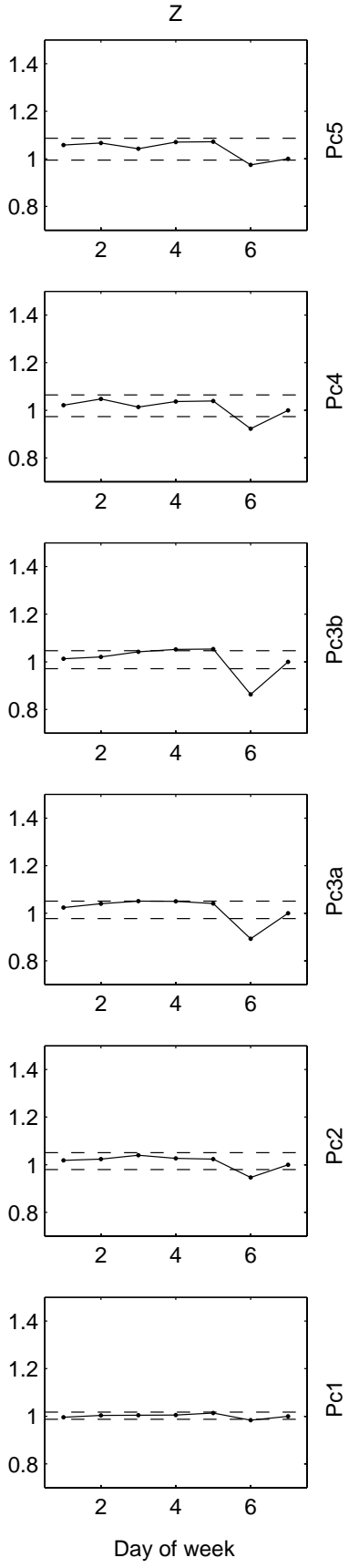

Fig. 3. Weekly variation of the nighttime average power of magnetic field components in different frequency bands at Station A (50\% of original spectra). 
(a)
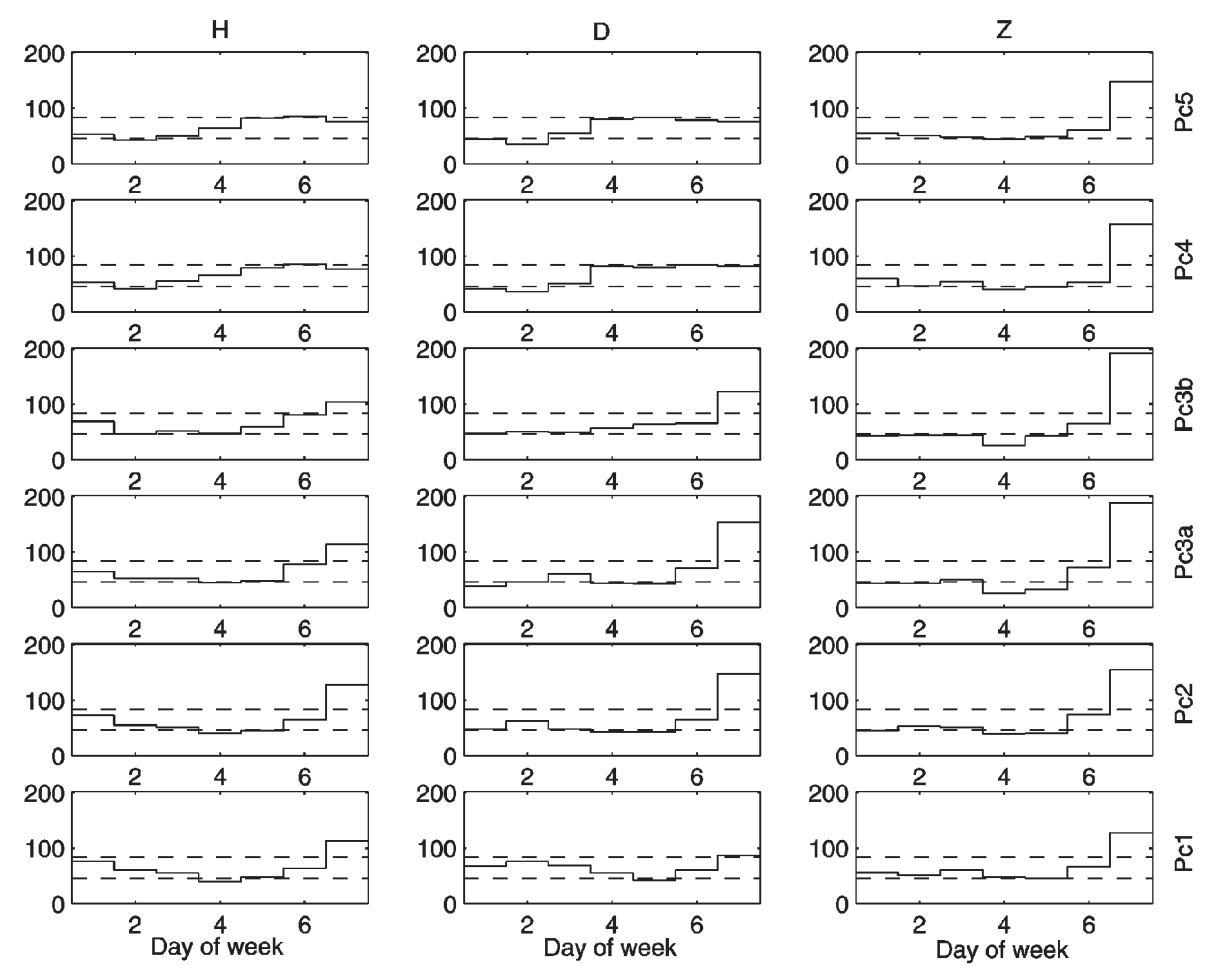

Station A 6-18 LT

(b)
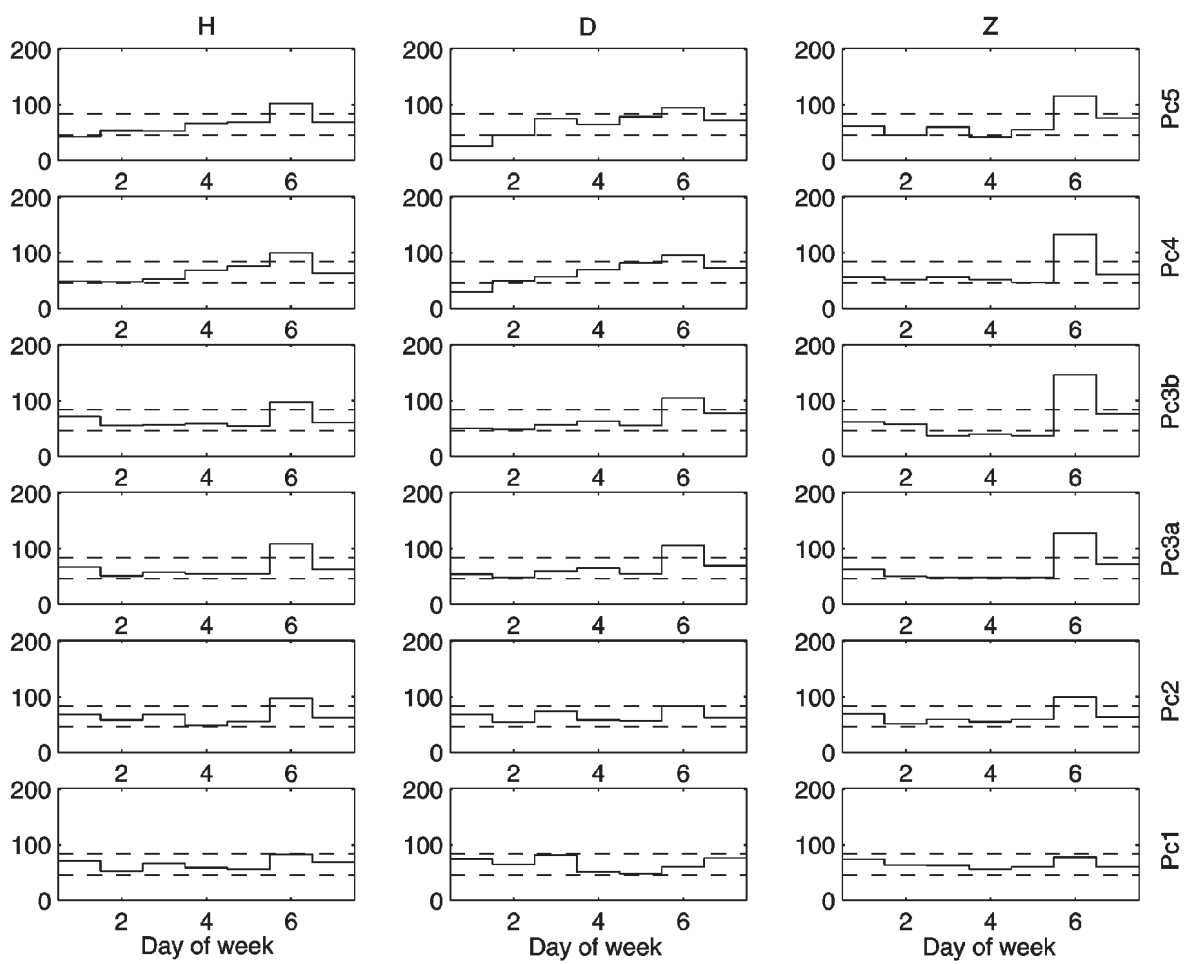

Station A 18-6 LT

Fig. 4. Weekly distribution of the lowest values of power (5\% of the whole population) in different frequency bands at Station A. Dashed lines identify the $99 \%$ confidence interval. (a) daytime interval; (b) nighttime interval. 
(a)
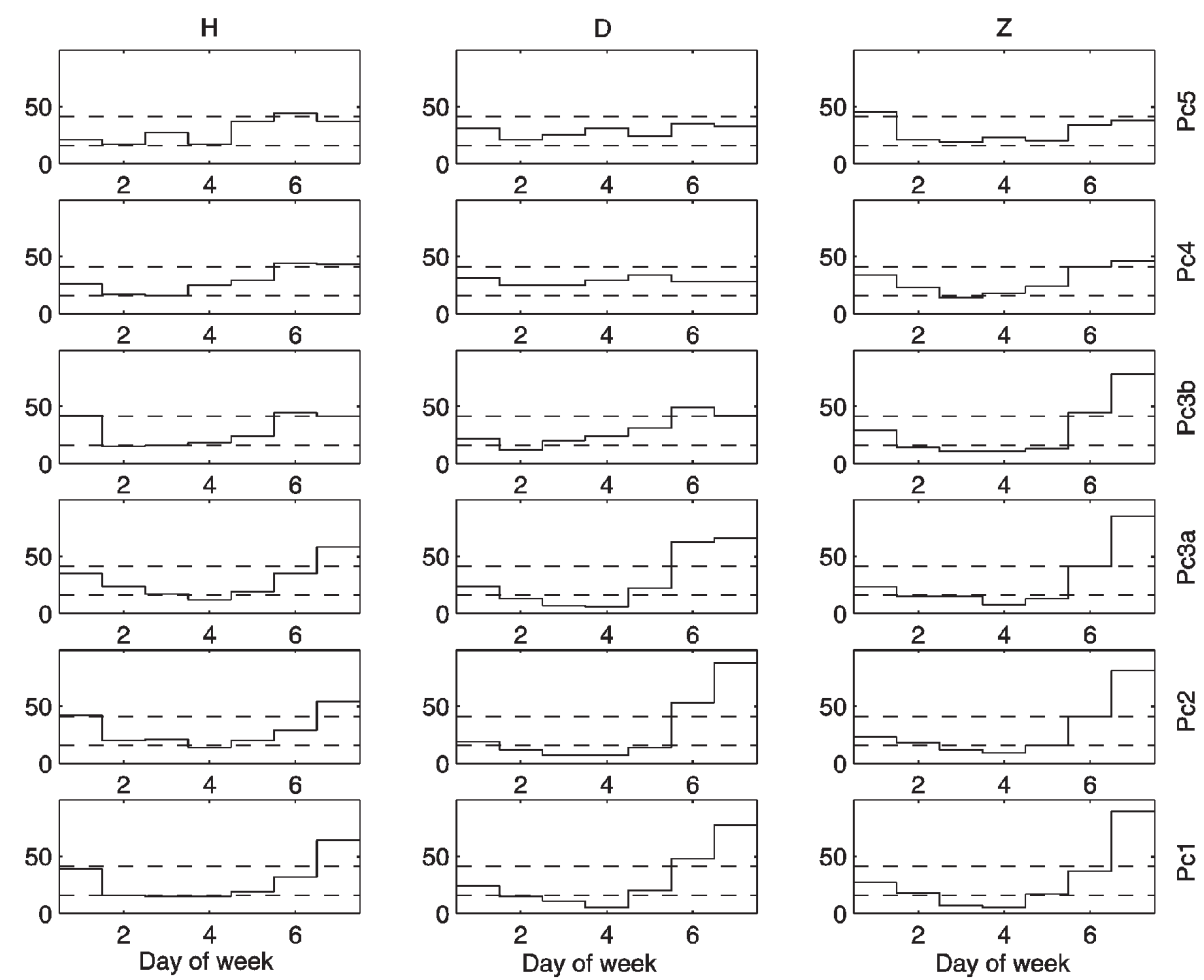

Station C 6-18 LT

(b)
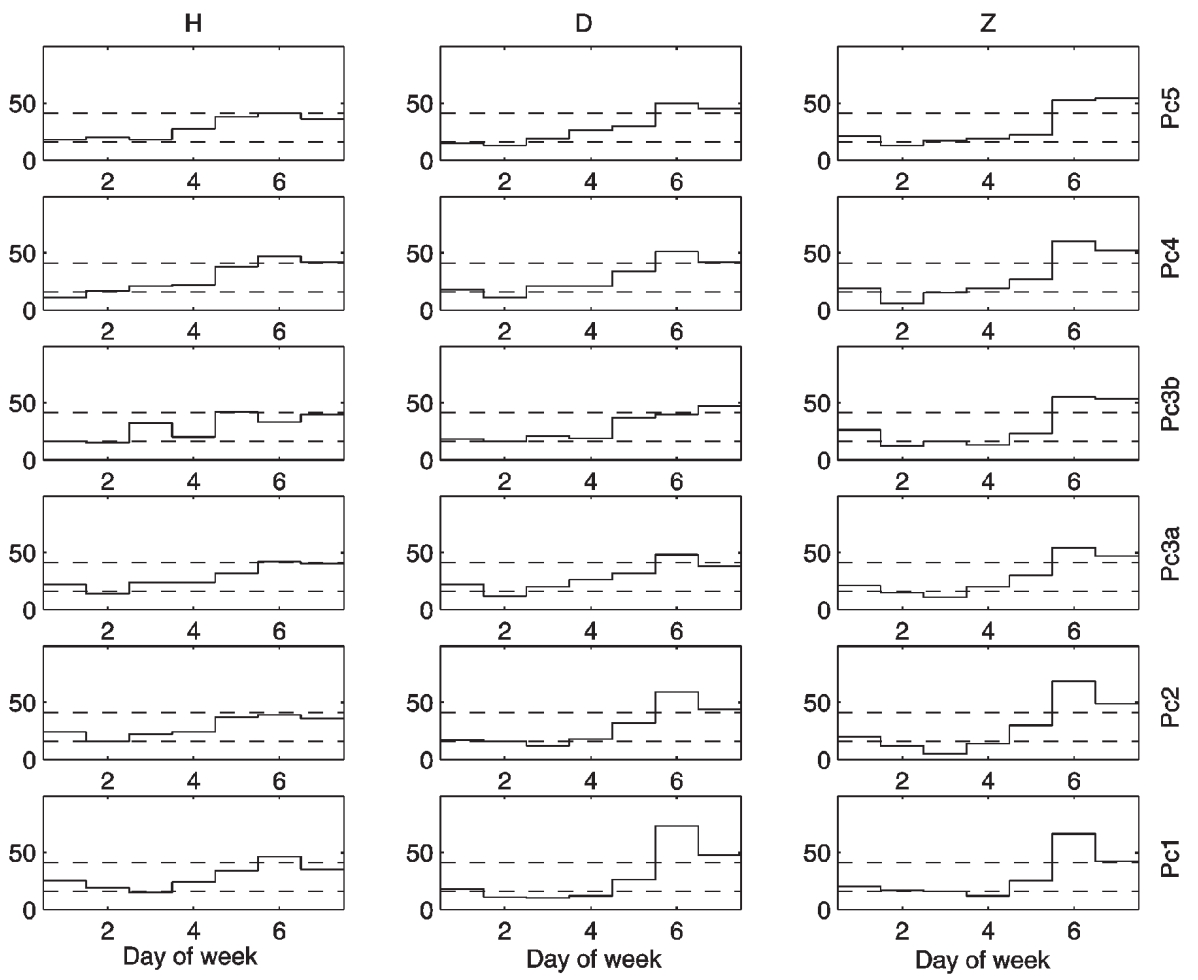

Station C 18-6 LT

Fig. 5. Weekly distribution of the lowest values of power (5\% of the whole population) in different frequency bands at Station C. Dashed lines identify the $99 \%$ confidence interval. (a) daytime interval; (b) nighttime interval. 
and are detected in both the horizontal components ( $H$ and $D)$, while Pc3b events typically have higher frequency ( $\sim 40-80 \mathrm{mHz}$, between latitudes of $\left.\sim 35^{\circ}-40^{\circ}\right)$ and appear much more sharply on $H$. Signal amplitudes typically overcome the noise level at least by a factor of 10 in the horizontal components, while no significant signal is detected along $Z$ (mostly for the effects produced by induced currents inside the Earth). During nighttime intervals, damped Pi2 fluctuations (6.6-25 mHz) associated with geomagnetic bays are often detected around local midnight (Villante et al., 1992). In the Pc5 range (1-6.7 $\mathrm{mHz}$ ) the statistical occurrence of power enhancements at discrete frequencies $(\sim 1.1,1.7,2.3,2.8$ and $3.7 \mathrm{mHz}$; Francia and Villante, 1997, Villante et al., 2001) has been interpreted in terms of ground signatures of magnetospheric cavity/waveguide modes driven by solar wind pressure pulses.

\section{Experimental results}

Micropulsation measurements have been conducted for several months (2000-2002) at several suitably chosen places in Western Europe ( $\mathrm{L} \sim 1.6-1.9$, typically several $\mathrm{km}$ far from populated areas and electric railways). The instrumentation basically consists of fluxgate magnetometers sampled at $1 \mathrm{~s}$. Power spectra of the geomagnetic field components were computed over consecutive 4-min intervals for local daytime (6-18 LT) and nighttime hours (18-6 LT). The spectra were evaluated in the frequency range $4-500 \mathrm{mHz}$, with a sampling of $4 \mathrm{mHz}$, by using the maximum entropy method with an autoregression order equal to 30 . We further integrated each hourly spectrum over frequency ranges that approximately correspond to the usual Pc1-Pc4 classification scheme. In addition, we separated the Pc3 band in two different frequency intervals (20-45 and 45-100 $\mathrm{mHz}$ ) in which $\mathrm{Pc} 3 \mathrm{a}$ and Pc3b would be preferentially expected. At lower frequencies, the power spectra were computed with the same technique over 1-h intervals considering as initial data the 15-s averages of the geomagnetic field components. Several other techniques for the power spectra evaluation have been adopted with similar results.

Our results are organized in six frequency bands: Pc1 (200-500 mHz), Pc2 (100-200 mHz), Pc3a $(45-100 \mathrm{mHz})$, Pc3b (20-45 mHz), Pc4 (5-20 mHz), Pc5 (1.6-5 mHz). Obviously, fluxgate measurements are poorly accurate at the highest frequencies; so the results obtained in Pc1 band should be considered only indicative. In the following we compare the results obtained at three sites in Italy, Austria and Hungary; however, similar results were obtained also at other stations. The best data coverage (Station A, Italy, 50 $\mathrm{km}$ far from electric railway) has $\sim 92 \%$ of expected measurements.

In general, man-made disturbances are expected to perturb electromagnetic measurements on a wide range of temporal scales (at least from daily to seasonal). On the other hand, natural signals are also expected to show daily, seasonal and solar cycle variations (Jacobs, 1970). Therefore, we found it useful to focus our attention mostly on the analysis of the weekly variation which is better related to artificial effects.

The average power values as organized in terms of the weekdays (Monday=1) are shown in Fig. 1 for station A. These averages have been obtained after removing, for each frequency band, component, and weekday, the $10 \%$ highest power values; as a matter of fact, this procedure accounts for extreme power levels associated with peculiar events, such as geomagnetic storms, highly localized artificial disturbances, and major micropulsation activity. Dashed lines in Fig. 1 identify the region of $99 \%$ occurrence computed from randomly selected hourly powers. In addition, in order to provide the same visual representation for equal relative variations, we normalized weekday values to the Sunday value, and chose the same vertical limits $(0.7-1.5)$ for all panels.

As shown in Fig. 1, daytime results reveal in the $Z$ component (which is much less influenced by natural signals of external origin), in any frequency band, a clear weekly modulation with minimum power values on Sundays, and reduced power levels on Saturdays. In the Pc2 band (and, to some extent, Pc1 band), where natural signals rarely occur at low latitudes, clear evidence for a weekly variation can also be identified in the horizontal components. Conversely, at lower frequencies, the horizontal components show more dramatic natural variations which overcome the possible effects of the working days contamination.

Figure 2a shows the results obtained for the same station and time interval after removing the $50 \%$ highest power values. This procedure practically removes most effects of the natural micropulsation activity. As can be seen, a clear weekly variation now explicitly appears on horizontal components also in the Pc3a and $\mathrm{Pc} 3 \mathrm{~b}$ bands. The ratio $\mathrm{R}$ between the Monday through Friday average value and the Sunday value can be considered indicative of the additional contamination during working days. At Station A, R has a maximum value in the Pc3a band $(\sim 1.13$, on $H$ and $D ; \sim 1.17$, on $Z$ ). In the Pc4 and Pc5 band the weekly modulation still appears only in the $Z$ component, suggesting a significant contribution of longer term natural signals in the horizontal components. Figure $2 \mathrm{~b}$ shows the results obtained at Station B (Hungary): as can be seen, the weekend effect is clear in the Pc1-Pc3 band while it vanishes in the Pc4-Pc5 band.

Figure 3 (Station A) shows the results that are typically obtained during nighttime intervals: as can be seen, they confirm in the $Z$ component a clear weekend effect and suggest Saturday nights as the quietest intervals. In this case the manmade contamination in the $\mathrm{Pc} 3 \mathrm{~b}$ band reaches $\mathrm{R} \sim 1.19$ (with respect to the Saturday value).

Figure 4 shows the results of an independent test (Station A) which reinforce the conclusions of the previous paragraph and suggest some additional interesting features. In this case we selected for each component and frequency band, the $5 \%$ of hourly intervals that correspond to the lowest power values. In agreement with previous results, their distributions vs. week days (dashed lines in Fig. 4 identify the theoretical $99 \%$ confidence interval for a flat occurrence probability) clearly confirm that the lowest power levels are 
(a)
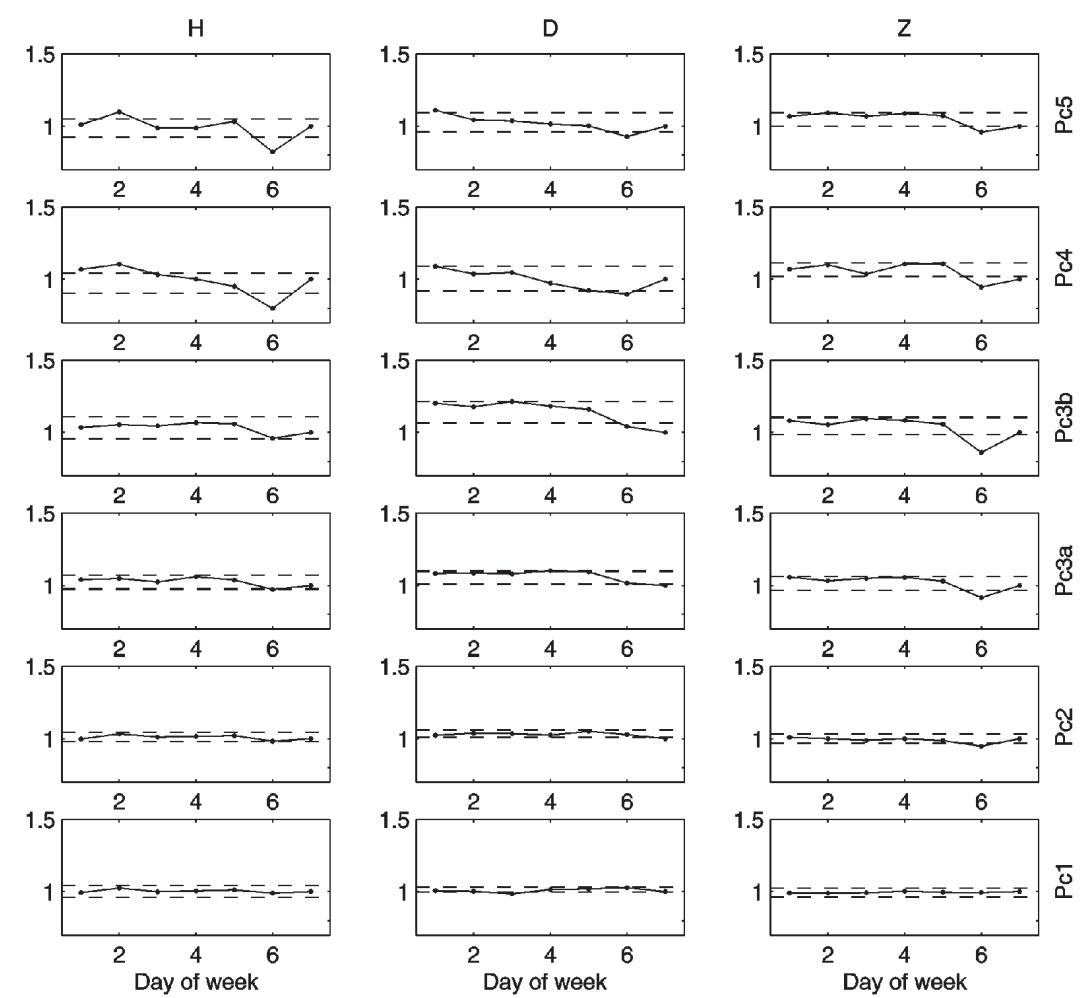

Station A (50\%) 22-2 LT

(b)

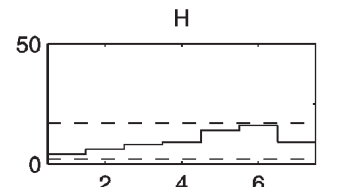

D
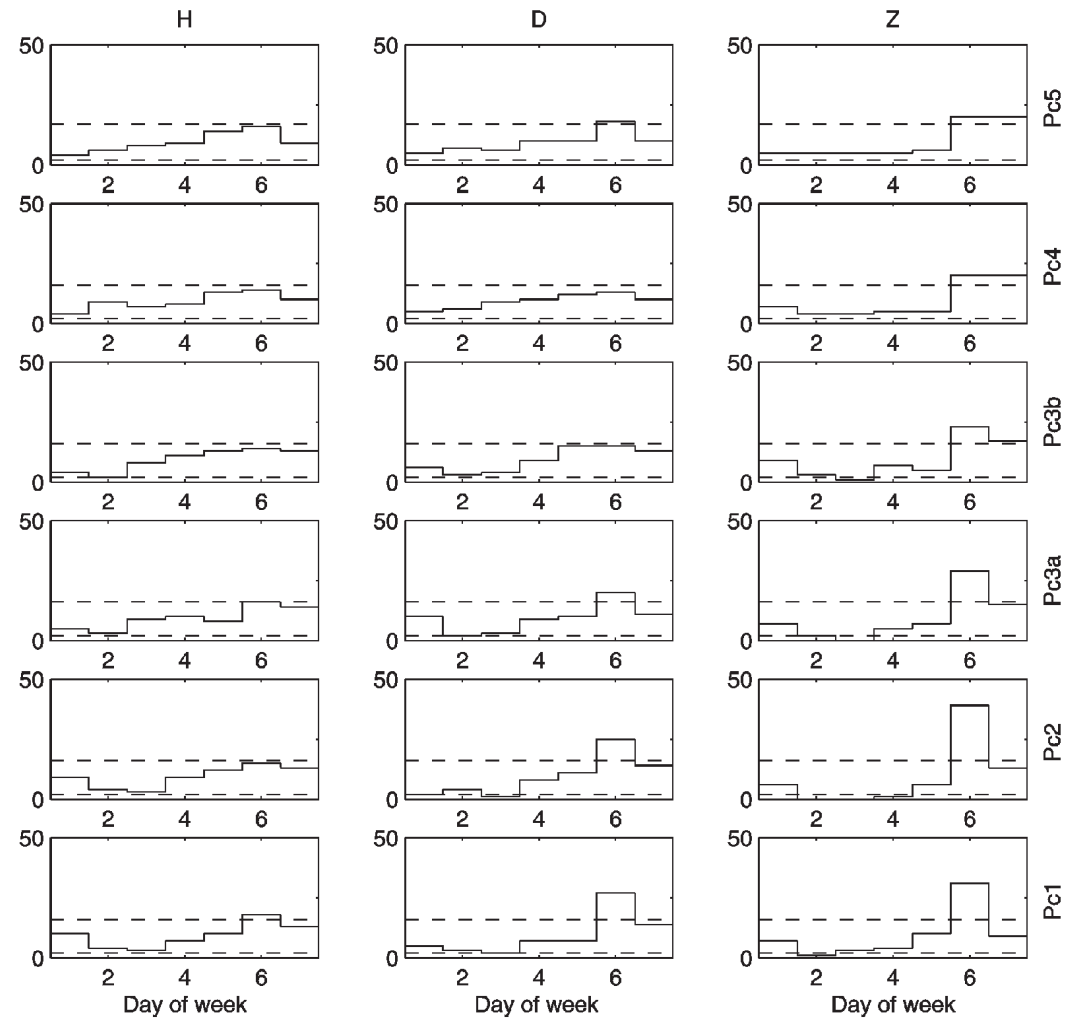

Station C 2-6 LT

Fig. 6. (a) Weekly variation of the average power (22-2 LT) of magnetic field components in different frequency bands at Station A (50\% of original spectra). (b) Weekly distribution of the lowest values of power (5\% of the whole population) in different frequency bands at Station C (2-6 LT). 
(a)
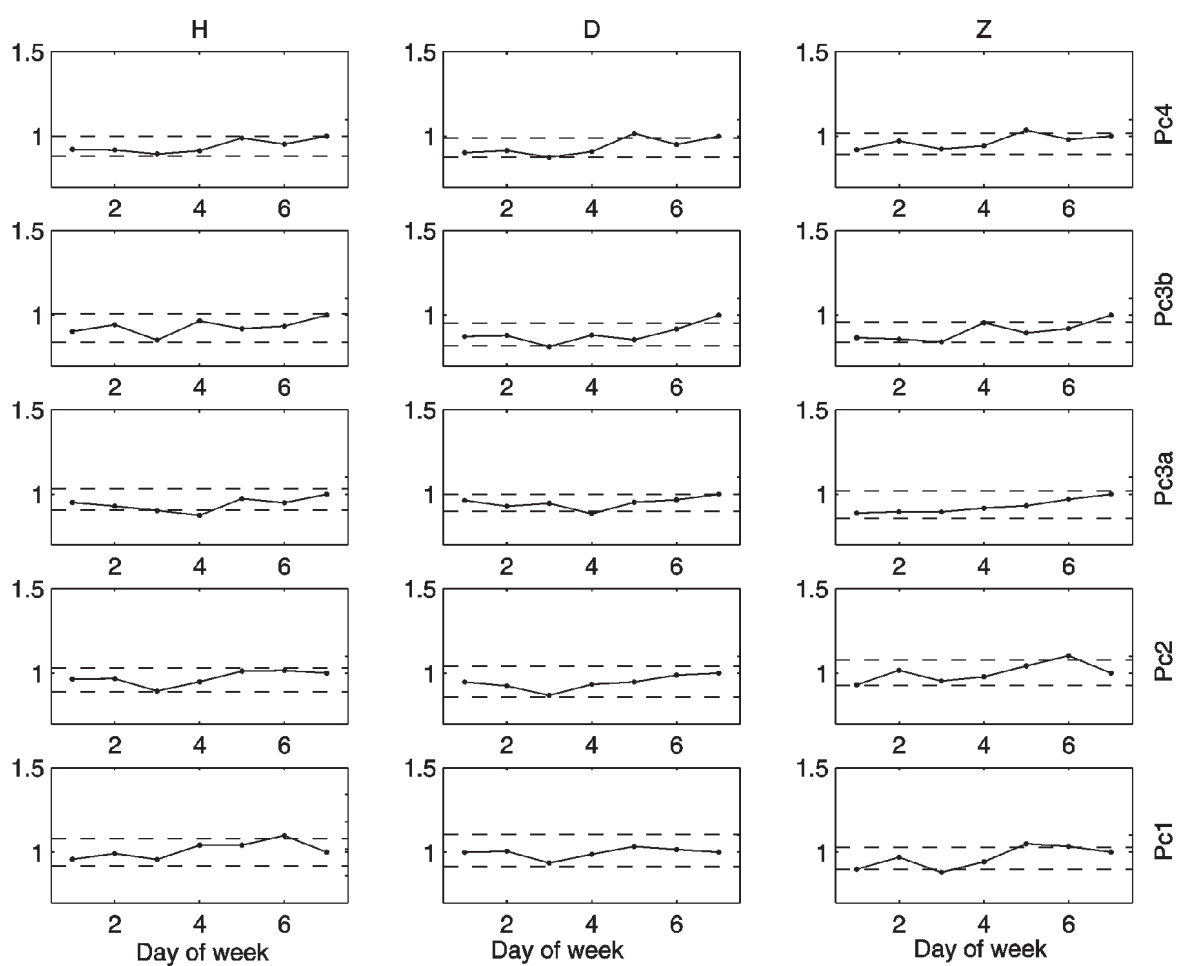

Terra Nova bay $(50 \%) 4-8 ; 16-20$ LT

(b)
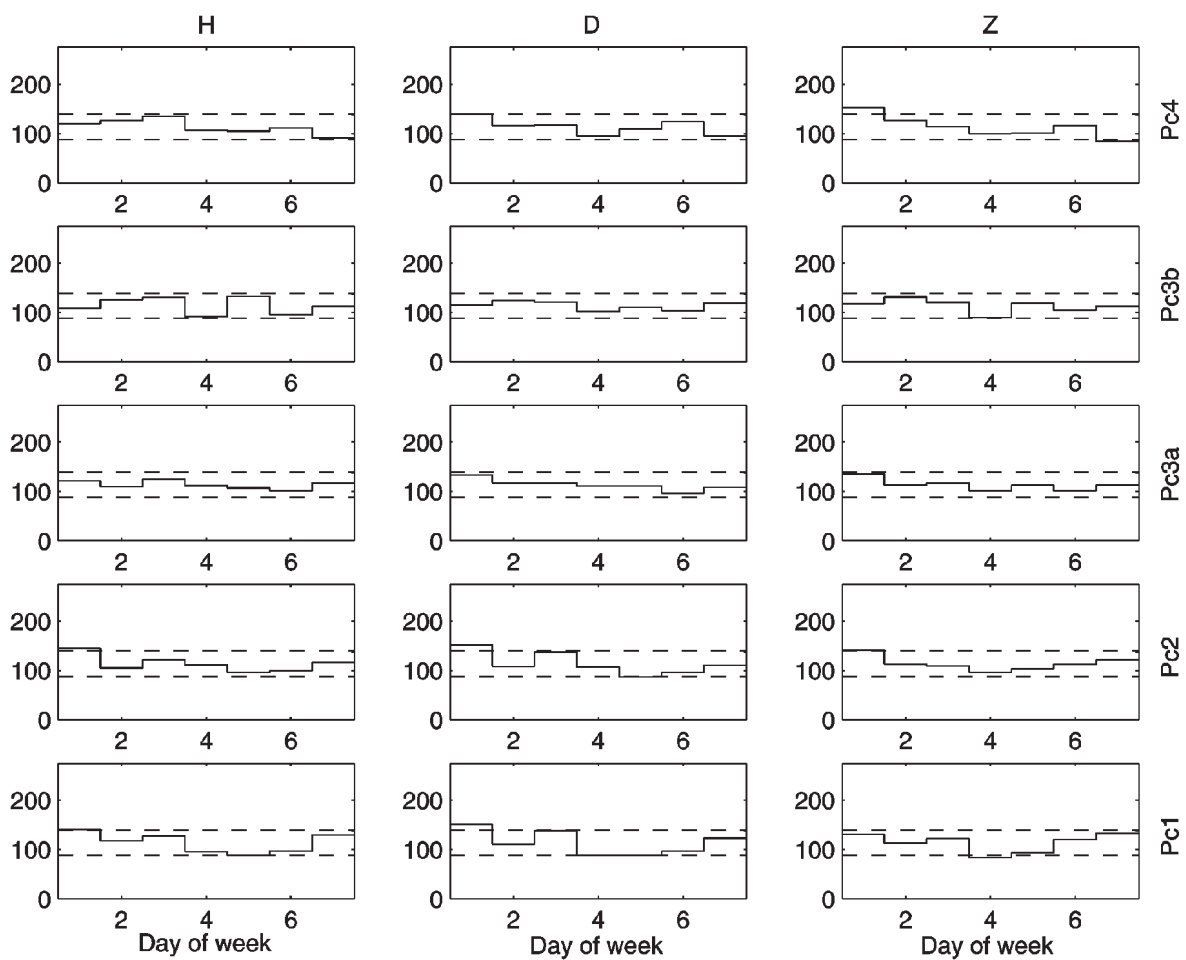

Terra Nova bay

Fig. 7. (a) Weekly variation of the average power of magnetic field components in different frequency bands at Terra Nova Bay (Antarctica, $50 \%$ of original spectra). Dashed lines identify the $99 \%$ confidence interval. (b) Weekly distribution of the lowest values of power (5\% of the whole population) in different frequency bands at Terra Nova Bay (Antarctica). Dashed lines identify the $99 \%$ confidence interval. 
preferentially associated with Sundays (Fig. 4a) and Saturday nights (Fig. 4b).

Figure 5 shows that similar results are obtained at Station $\mathrm{C}$ (Austria), where the percentage of quiet hours on Monday morning are appreciably greater than in other days (a feature that also emerges at other sites).

In order to investigate the possible disappearance (or significant reduction) of the man-made contamination during shorter intervals in the middle of the night, we conducted the same kind of analysis for different time intervals in the nighttime sector. As typical examples we show the results obtained at station A (22-2 LT, Fig. 6a) and station C (2-6 LT, Fig. 6b): as can be seen, they clearly reveal the same effects obtained for the entire time sector (Fig. 3 and Fig. 5b).

In Antarctica, at Terra Nova Bay (geom. lat. $80^{\circ} \mathrm{S}$ ), ULF measurements are conducted by means of a search coil instrument originally sampled at $10 \mathrm{~Hz}$ and then averaged and stored at $1 \mathrm{~Hz}$. For the present investigation 1-s data (19941998) have been processed; obviously, search coil measurements do not extend to the lowest frequencies. Due to the Earth's rotation, Terra Nova Bay has a variable distance, through the day, from the cusp projection and is located inside the polar cap during the major part of the day. As a consequence, the ULF activity often shows a significant power enhancement (approximately of an order of magnitude in the Pc3 and Pc4 bands) around local magnetic noon, when the station approaches closed field lines (Villante et al., 2000a, 2000b). On the other hand, the effects of the substorm occurrence might be expected in the midnight sector. So, in order to evaluate the effects of the possible contamination from artificial signals, we examined ULF measurements obtained far from local noon and midnight. As a matter of fact, a visual inspection of experimental results (Fig. 7) does not reveal in this case any significant weekly variation of the spectral power.

\section{Discussion}

A careful evaluation of the possible contamination of natural ULF signals from artificial man made disturbances represents an interesting aspect of geophysical science in that for several applications (magnetospheric physics, magnetotellurics, possible earthquakes precursors, biological aspects, etc.), it is important to conduct ULF measurements not far from densely populated areas. Obviously, the contamination level is strongly dependent upon site, technical apparatus and data processing. However, we found common characteristics that can be considered indicative of the level of man-made contamination in populated areas in western Europe, namely the following:

In the micropulsation regime, the working day contamination is detected even at suitably selected sites in populated areas. It basically consists of reduced power levels, as well as of greater percentages of quiet hours during weekends (and, to a lesser extent, Monday morning). The reduced power level during weekends can hardly be imputed to the effects of electrified railways in that railway traffic is not much less intense during the weekends. Rather, it might suggest electromagnetic contamination from local industries during working days. Nevertheless, since lower weekend signals are also detected during short time intervals in the middle of the night, we tentatively speculate a possible relationship between the experimental results and a reduced power generation during the entire weekend in European countries.

Typically, the noise amplitude is order of magnitudes lower than significant natural signals. In this sense it does not affect the scientific analysis of single events. It is clear, however, that a preliminary analysis of the man made contamination is important before drawing conclusions on the short- and long-term modulation of the ULF activity. For example, any analysis of the weekly distribution of automatically selected events (Fraser-Smith, 1979; Tsirs and Loginov, 1985; Vero, 1986) might be influenced by the different noise levels on different days. A similar conclusion holds for the spectral analysis of long time series of the integrated power whose results might be significantly affected by the reduced weekend levels.

The possible modulation of the geomagnetic activity indices have been discussed by several authors with some controversial results. Fraser-Smith (1979) suggested a possible weekend increase in Ap and aa indices since 1940. He proposed that the smaller geomagnetic activity during weekdays might reflect a higher power line radiation that would affect magnetospheric processes suppressing natural disturbances. Recently, however, Karinen et al. (2002) reexamined the weekend effect of the Ap and aa indices and concluded that the weekend/weekday difference should be considered as a purely statistical nature.

At Antarctic latitudes our observations do not support any firm evidence for a significant man-made contamination in the ULF band, suggesting a negligible influence from remote areas. It is, however, interesting to remark that, at higher frequencies, Park and Miller (1979) found a distinct Sunday minimum in the VLF wave activity in Antarctica (19741975) and interpreted the experimental results in terms of a reduced power consumption in conjugate regions in Canada.

Acknowledgements. This research activity is supported by MIUR/COFIN, PNRA (Programma Nazionale Ricerche in Antartide) and Consorzio Area di Ricerca in Astrogeofisica. V. W. acknowledges financial support by the Hungarian Research Fund OTKA T032173, TS40848. The editor in chief thanks two referees for their help in evaluating this paper.

\section{References}

Breus, T. K., Cornelissen, G., Halberg, F., and Levitin, A. E.: Temporal associations of life with solar and geophysical activity, Ann. Geophysicae, 13, 1211, 1995.

Francia, P. and Villante, U.: Some evidence for ground power enhancements at frequencies of global magnetospheric modes at low latitudes, Ann. Geophysicae, 15, 17, 1997.

Fraser-Smith, A. C.: A weekend increase in geomagnetic activity, J. Geophys. Res., 84, 2089, 1979. 
Fraser-Smith, A. C., Bernardi, A., McGill, P. R., Ladd, E., Helliwell, R. A., and Villard, O. G.: Low frequency magnetic field measurements near the epicenter of the Ms=7.1 Loma Prieta earthquake, Geophys. Res. Lett., 17, 1465, 1990.

Fraser-Smith, A. C., McGill, P. R., Helliwell, R. A., and Villard, O. G.: Ultra-low frequency magnetic field measurements in southern California during the Northridge earthquake of 17 January 1994, Geophys. Res. Lett., 21, 2195, 1994.

Gotoh, K., Akinaga, Y., Hayakawa, M., and Hattori, K.: Principal component analysis of ULF geomagnetic data for Izu islands earthquakes in July 2000, J. Atmosph. Electr., 22, 01, 2002.

Hayakawa, M., Kawate, R., Molchanov, O. A., and Yumoto,K.: Results of ultra-low-frequency magnetic field measurements during the Guam earthquake of 8 August 1993, Geophys. Res. Lett., 23, 241, 1996.

Jacobs, J. A.: Geomagnetic micropulsations, in physics and chemistry in space, edited by J.G. Roeder (Springer-Verlag), vol. 1, 1970.

Karinen, A., Mursula, K., Ulich, T., and Manninen, J.: Does the magnetosphere behave differently on weekends? Solar Cycle and Space Weather Conference, ESA SP-477, 439, 2002.

Lanzerotti, L. J., Maclennan, C. G., and Webb, D. C.: Comparisons of inferred total plasmasphere content with measured plasma density profiles, J. Geophys. Res., 84, 2648, 1979.

Meloni, A., Medford, L. V., and Lanzerotti, L. J.: Geomagnetic anomaly detected at hydromagnetic wave frequencies, J. Geophys. Res., 90, 3569, 1985.

Molchanov, O. A., Kopytenko, Yu. A., Voronov, P. M., Kopytenko, E. A., Matiashvili, T. G., Fraser-Smith, A. C., and Bernardi, A.: Results of ULF magnetic field measurements near the epicenters of the Spitak $(\mathrm{Ms}=6.9)$ and Loma Prieta $(\mathrm{Ms}=7.1)$ earthquakes: Comparative analysis, Geophys. Res. Lett., 19, 1495, 1992.

Nagao, T., Enomoto, Y., Fujinawa, Y., Hata, M., Hayakawa, M., Huang, Q., Izutsu, J., Kushida, Y., Maeda, K., Oike, K., Uyeda, S., and Yoshino, T.: Electromagnetic anomalies associated with 1995 Kobe earthquake, J. Geodyn., 33, 401, 2002.

Park, C. G. and Miller, T. R.: Sunday decrease in magnetospheric VLF wave activity, J. Geophys. Res., 83, 943, 1979.

Pilipenko, V. A. and Fedorov, E. N.: Magnetotelluric sounding of the crust and hydromagnetic monitoring of the magnetosphere with the use of ULF waves, Ann. Geofis., 36, 19, 1993.

Ptitsyna, N. G., Villoresi, G., Kopytenko, Y. A., Kudrin, V. A., Tyasto, M. I., Kopytenko, E. A., Iucci, N., Voronov, P. M., and, Zaitsev, D. B. : Coronary heart diseases: An assessment of risk associated with work exposure to ultra-low frequency magnetic fields, Bioelectromagnetics, 17, 436, 1996.
Tsirs, G. P. and Loginov, G. A.: Peculiarities of week variations of Pc 1 and Pi 2 geomagnetic pulsations, Geomagn. Aeron., 25, $165,1985$.

Vellante, M.: Some theoretical aspects of the two-level magnetovariational metod, Ann. Geofis., 40, 1445, 1997.

Vellante, M., De Lauretis, M., Förster, M., Lepidi, S., Zieger, B., Villante, U., Pilipenko, V. A., and Zolesi, B.: Geomagnetic field line resonances at low latitudes: Pulsation event study of 16 August 1993, J. Geophys. Res., 107 (A5), doi:10.1029/2001JA900123, 2002.

Vero, J.: Experimental aspects of low-latitude pulsations-a review, J. Geophys., 60, 106, 1986.

Villante, U. and Vellante, M.: Experimental aspects of low latitude ground pulsations, in solar system plasma physics, conference proceedings, edited by F. Mariani and N. F. Ness (SIF, Bologna), 56, 189, 1997.

Villante, U. and Vellante, M.: An analysis of working days contamination in micropulsation measurements, Ann. Geofis., 41, 325, 1998.

Villante, U., Vellante, M., De Biase, M., Lanzerotti, L. J., and Medford, L. V.: Pi2 pulsations at separated sites $\left(\Delta \Phi=90^{\circ}\right)$ : A comparison between mid- and low-latitude observations, Ann. Geophysicae, 10, 472, 1992.

Villante, U., Vellante, M., De Lauretis, M., Cerulli-Irelli, P., Lanzerotti, L. J., Medford, L. V., and Maclennan, C. G.: Surface and underground measurements of geomagnetic variations in the micropulsations band, Geophys. Prospect., 46, 121, 1998.

Villante, U., Lepidi, S., Francia, P., Vellante, M., Meloni, A., and Palangio, P.: ULF fluctuations at Terra Nova Bay (Antarctica), Ann. Geofis., 43, 217, 2000a.

Villante, U., Vellante, M., and De Sanctis, G.: An analysis of Pc3 and Pc4 pulsations at Terra Nova Bay (Antarctica), Ann. Geophysicae, 18, 1412, 2000b.

Villante, U., Francia, P., and Lepidi, S.: Pc5 geomagnetic field fluctuations at discrete frequencies at a low latitude station, Ann. Geophysicae, 19, 321, 2001.

Villoresi, G., Kopytenko, Y. A., Ptitsyna, N. G., Tyasto, M. I., Kopytenko, E. A., Iucci, N., and Voronov, P. M.: The influence of geomagnetic storms and man-made magnetic field disturbances on the incidence of myocardial infarction in St. Petersburg (Russia), Physica Medica, 4, 107, 1994.

Webb, D. C., Lanzerotti, L. J., and Park, C. G.: A comparison of ULF and VLF measurements of magnetospheric cold plasma densities, J. Geophys. Res., 82, 5063, 1977. 